
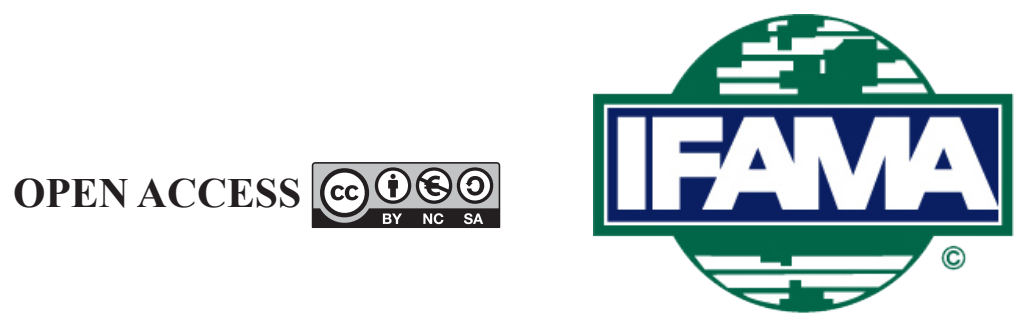

International Food and Agribusiness Management Review

Volume 21 Issue 8, 2018; DOI: 10.22434/IFAMR2017.0059

Received: 30 June 2017 / Accepted: 11 June 2018

\title{
Patterns in sustainable relationships between buyers and suppliers: evidence from the food and beverage industry \\ RESEARCH ARTICLE
}

\author{
Suzanne van der Werffa, Jacques Trienekens ${ }^{\oplus b}$, Geoffrey Hagelaar ${ }^{\circledR c}$, and Stefano Pascucci ${ }^{\mathrm{d}}$ \\ ${ }^{a}$ Researcher, ${ }^{b}$ Professor, and ${ }^{c}$ Associate Professor, Business Management and Organisation \\ group, Wageningen University, Hollandseweg 1, $6706 \mathrm{KN}$ Wageningen, the Netherlands \\ ${ }^{d}$ Professor, University of Exeter - Business School, Penryn Campus, \\ G16 The SERSF Building, Cornwall, United Kingdom
}

\begin{abstract}
Although research on sustainable procurement is increasing, little empirical research has been done on how sustainable procurement is established between companies. Therefore, drawing on supply chain management and purchasing management literature, this study explores how food industries manage sustainable supplier relationships. Through the identification of company clusters with typical sustainable procurement approaches, the paper contributes to the supply chain management literature. A questionnaire is applied to gather data amongst Dutch Food and Beverage companies from which 62 could be used for the analyses (effective response rate $28.9 \%$ ). Cluster analysis revealed four types of companies with distinctive sustainable procurement relationships: market relationships (arms-length), sustainability leader, one-sided sustainability (interested supplier but less interested buyer), and inconclusive sustainability (buyer and suppliers only made a start). As the implementation of sustainable procurement remains low in practice, insights from this study are important for managers.
\end{abstract}

Keywords: supplier relationships, procurement, sustainability, food industry, performance JEL code: L22, M14, Q001

\footnotetext{
(1)Corresponding authors: jacques.trienekens@wur.nl; geoffrey.hagelaar@wur.nl
} 


\section{Introduction}

Sustainability is not a company stand-alone performance, but is achieved in the supply chain with suppliers' support (Jabbour et al., 2014). Sustainability goals on the economic, environmental and social dimensions are taken into account on a supply chain level (Govindan et al., 2016), presupposing collaboration between the different chain members which in mutual coordination enable sustainable development (Govindan et al., 2016; Seuring and Muller, 2008). Building effective and efficient supply chain relationships and collaborations is stated to enhance sustainable performance (Gellynck et al., 2012; Govindan et al., 2016; Rota et al., 2013). Especially the purchasing function plays a critical role in this (Chkanikova, 2016). Eventually raw material, components and (half-)products are introduced via the purchasing function and sustainability requirements on suppliers and possibly on suppliers' suppliers are transferred to them via procurement (Zsidisin and Hendrick, 1998). Sustainable procurement is defined as the simultaneous pursuit of economic, environmental and social development objectives through the purchasing process (Walker et al., 2012).

Although procurement trajectories can be characterised by a high level of uncertainty, risk and technical complexity, these trajectories become even more challenging in the context of sustainability issues (Bruno, et al., 2018). Research into such trajectories is scarce (Bruno et al., 2018; Ellram et al., 2007; Nordin and Angdal, 2008) and inconclusive on how purchasing relationships concerning sustainability are managed and could be managed (Chkanikova, 2016). The necessity of developing collaboration into strong relationships to achieve sustainability is highlighted by some authors (Caniëls and Gelderman, 2007; Duffy et al., 2013; Gold et al., 2010; Seuring and Muller, 2008) whilst collaboration is found not always appropriate by others (Cox, 1996; Dyer and Singh, 1998; Lambert and Cooper, 2000), whereas the use of power is advocated to force suppliers to act sustainable (e.g. Awaysheh and Klassen, 2010; Hoejmose et al., 2013).This current lack of conclusiveness of empirical research into buyer-supplier relationships and how they can foster sustainability has left researchers undecided on what is important in the buyer-supplier relationship to achieve sustainability (Duffy et al., 2013; Grimm et al., 2014; Oruezabala and Rico, 2012). Likewise, little empirical research has been done on how actually supply chain relationships are managed and how supply chain activities as a whole are being integrated (Varoutsa and Scapens, 2015). As current empirical insights into supply chain relations (also) with respect to sustainable procurement are lacking, this paper uses an inductive approach to enhance existing theory and help to explain actual sustainable supply chain functioning. The guiding research question is: which patterns from the perspective of sustainability can be identified in procurement relationships and to which sustainability performance does that lead?

This study focuses on the actual relationships between buyers and suppliers with respect to sustainable purchasing, which buyer's and supplier's internal and their relational characteristics play a role and to which sustainability performance that leads. The inductive approach will result in the identification of patterns of relationships comprising constellations of companies' internal and relational characteristics and their sustainability performance. This research contributes theoretically to sustainable supply chain management literature to present a variety of patterns of supplier-buyer relationships in which each pattern illustrates a specific constellation of characteristics of companies and of their interrelation in conjunction with sustainable performance. These patterns make clear how in complex procurement trajectories sustainable perspectives are incorporated (Brammer and Walker, 2011; Preuss, 2009). As the implementation of sustainable procurement remains low in practice (Genovese et al., 2013; Schneider and Wallenburg, 2012), insights from this study are also important for managers. By presenting sustainability relationship patterns managers are supported to recognise and form relationships to improve sustainability (Pagell et al., 2010).

This paper is structured as follows. In the literature review (Section 2), the procurement practice is explored from the perspective of the buyer-supplier relationship, characteristic of buying and supplying companies, the level of integration of sustainable procurement and sustainable performance. The results of this research are based on a survey sent to 214 companies from which 62 could be used for the analyses (effective response rate 28.9\%). The research methodology will be explained in Section 3. Section 4 presents a Principal Component 
Analysis and the cluster analysis of the sustainable procurement practices in presented in Section 5. We will close this article with conclusions and discussion on the findings.

\section{Literature}

Sustainable procurement is a field that has received growing attention within the academic community during the last decade (Krause et al., 2009; Walker et al., 2012). Nevertheless, the existing literature is diverse and researchers have acknowledged the complexity and dynamic nature of sustainable procurement (Hoejmose and Adrien-Kirby, 2012). Some topics have received considerably more attention than others, such as internal and external drivers for sustainable procurement, and the impact on performance and barriers for the implementation of sustainable procurement (Hoejmose and Adrien-Kirby, 2012). When defining sustainability in terms of the triple P encompassing the social, economic and environmental dimension, surely, most attention has been given to green, environmental, procurement issues (Carter and Easton, 2011). One of the important research gaps (Hoejmose and Adrien-Kirby, 2012; Sarkis et al., 2011) this article will pay attention to is research into characteristics of buyer-supplier relationships and especially into how these can foster sustainability (Duffy et al., 2013; Grimm et al., 2014; Oruezabala and Rico, 2012). Fostering sustainability within a relationship presupposes certain characteristics of the relationship itself, the holders of that relationship (buyer and supplier) and having insight in the level of sustainability which is fostered. The objective of this study was to relate company internal and relationships' characteristics to sustainability performance. The following literature review identifies the main constructs for our research.

\subsection{Buyer-supplier relationships characteristics}

Although several scholars identified the importance of buyer-supplier relationships for sustainability (e.g. Beske et al., 2014; Duffy et al., 2013; Gualandris et al., 2014; Schneider and Wallenburg, 2012), they remain undecided on what is important in the relationship to actually facilitate sustainable procurement (Grimm et al., 2014; Oruezabala and Rico, 2012). This literature search identifies important characteristics of buyer-supplier relationships from and their impact on sustainable supplier relationships. Power and dependency have often been recognised to be important aspects in buyer-supplier relationships (Kraljic, 1983) and more recently in understanding its connection with sustainability (e.g. Andersen and Skjoett-Larsen, 2009; Hoejmose et al., 2013). Furthermore, trust and commitment are also central concepts (Wagner, 2011). Trust and commitment are considered crucial for a collaborative approach towards sustainability (Beske and Seuring, 2014; Carter and Jennings, 2002; Sarkis et al., 2011). Additionally, as stated by Fawcett et al. (2011), a basic requirement for buyer-supplier relationships is information exchange. Some scholars argue that the buyer-supplier relationship can also be influenced by the geographical distance between a buyer and supplier (Awaysheh and Klassen, 2010; Hoejmose et al., 2013). The final feature of a buyer-supplier relationship that will be taken into account is the presence of a code of conduct. Several scholars acknowledge the importance of codes of conduct (e.g. Beske and Seuring, 2014; Hoejmose and Adrien-Kirby, 2012; Wu and Pagell, 2011). They indicate how the value orientation of the purchasing company and its expectations from its suppliers (Amaeshi et al., 2008; Hoejmose and Adrien-Kirby, 2012), can have an influence on how the buyer-supplier relationship is shaped, and the level of sustainable procurement that is reached.

\subsection{Buyer and supplier characteristics impacting their relationships}

\section{- Buyer}

We identified the following characteristics from the literature: supplier management, corporate culture, stakeholder management, know-how and expertise. The first feature often identified as important in literature on sustainable procurement is 'supplier management'. This entails the processes of supplier selection, supplier development and supplier evaluation (Reuter et al., 2010). Due to the impact suppliers can have on the sustainability performance of a company (Ageron et al., 2012), supplier management is a crucial issue for a company aiming to maintain a strategically competitive position (Govindan et al., 2013). Moreover, 
the incorporation of sustainability criteria in the supplier selection process increases the complexity of the purchasing process and supplier management (Handfield et al., 2002), as more criteria need to be met. 'Corporate culture', the next buyers' feature, encompasses aspects related to how the company works. If top management support, a corporate history of working on sustainability issues and dedicated employees are present, the corporate culture can support sustainable procurement (Caniëls et al., 2013). Additionally, if the corporate culture supports cross-functional cooperation, the functional and corporate strategies are better aligned, which is of vital importance for business success (Boks, 2006; González-Benito, 2007). Furthermore, 'stakeholder management' entails understanding the role and influence of stakeholders such as consumers, governments, NGOs, activists and even competitors or shareholders (Crespin-Mazet and Dontenwill, 2012; Miemczyk et al., 2012; Schneider and Wallenburg, 2012). Companies may experience difficulties with implementing sustainable procurement if they do not conduct appropriate stakeholder management. Therefore, properly assessing stakeholders, prioritising them accordingly and engaging stakeholders in the purchasing process is of importance in this realm. Know-how and expertise of the buying company is the final feature to be included. The buying company needs to have knowledge on relevant sustainability practices in order to implement sustainable procurement and transfer this to its suppliers (Blome et al., 2014; Sucky and Durst, 2013).

\section{- Supplier}

Also in the case of a supplying company corporate culture is identified as a key feature to be taken into account. Similar to the buying company, a suppliers' sustainability is likely to vary depending on top management support, attitude of employees and corporate history of working with sustainability issues. Additionally, willingness to learn and to participate in sustainability initiatives from the buying company is an important aspect of corporate culture (Caniëls et al., 2013; Spekman and Carraway, 2006). Know-how and expertise, similar to the buying company, is included as well. Relevant knowledge and expertise were found to be positively related to suppliers' participation in sustainability initiatives (Caniëls et al., 2013). Finally, Grekova et al. (2014) and Caniëls et al. (2013) recognised suppliers' access to resources from buyers, NGOs or governments as potential constraints for sustainability. Because of low margins in many food industries, most companies have limited financial, human and technical resources available to invest in sustainability (Caniëls et al., 2013; Lee and Klassen, 2008).

\subsection{Maturity levels of sustainability}

In the previous sections, characteristics of buyers and suppliers and their relationships are identified as part of procurement practices. In our research we relate procurement practices to sustainability performance. The basic idea is similar to maturity models. In such models maturity of a company's sustainability state is determined by the integration of sustainability into the activities of a company and into their external relations (Müller and Pfleger, 2014). To illustrate the idea of such a model we present the four levels' maturity model of Baumgartner and Ebner (2010; and as used by e.g. Amini and Bienstock, 2014; Müller and Pfleger, 2014). They created a four-level maturity grid, in which level one stands for a rudimental level, where the company might begin to consider sustainability and where (if any) only mandatory regulations are adhered to. In the second level, the company complies with sustainability-related regulations and even goes slightly further, to differentiate itself from the competitors and to increase its credibility. Level three represents a substantial consideration and maturity of sustainability, which is often above the industry average. Companies are focussed on the external presentation of sustainability to substantially increase their credibility in society, but also aim at positively influencing the basic conditions of corporate sustainability in society. Finally, level four represents an outstanding effort towards sustainability and a sophisticated maturity. These companies show a highly developed sustainability commitment in order to become a market leader in sustainability 
issues (Baumgartner and Ebner, 2010). In this highest level, the company includes customers, suppliers and partners in sustainability practices and drives industry standards (Müller and Pfleger, 2014) ${ }^{1}$.

\section{Methodology and empirical strategy}

\subsection{Selection industry}

The connections between the buyer-supplier relationship, buyer and supplier characteristics and the level of sustainable procurement are explored by conducting a survey in a sample of Dutch companies operating in the food and beverages (F\&B) industry. In order to identify how buyer-supplier relationship can support sustainable procurement, this research aims to find companies with similar characteristics when it comes to buyer-supplier relationships and sustainable procurement. Although prior research has often considered multiple industries simultaneously, there has been an increasing call for industry specific research and applications (Carter and Easton, 2011; Hollos et al., 2012; Schneider and Wallenburg, 2012; Sucky and Durst, 2013; Tate et al., 2012). Indeed, sustainability practices vary per industry, due to the differences in external pressure and the relevancy of the three sustainability aspects (Tate et al., 2012). For example, the sustainable procurement profile of chemical companies will focus to a larger extent on environmental issues, whereas the labour-intensive textile industry will mainly focus on social issues (Carter and Easton, 2012; Schneider and Wallenburg, 2012). Thus, industry specific circumstances influence the integration of sustainable procurement practices in companies and are therefore relevant to take into account when considering the buyer-supplier relationship. Following these arguments, this research adopts a single industry approach. More specifically, in this research we use data and information derived from companies operating in the Dutch F\&B industry to perform our analysis on how buyer-supplier relationships can foster and facilitate sustainable procurement.

The Dutch F\&B industry is an appropriate industry to gain more insights into how buyer-supplier relationships can facilitate sustainable procurement. The F\&B industry is one of the largest industries in the Netherlands in terms of production and turnover (CBS, 2014), but also one of the most polluting industries (Grekova et al., 2014). Through all sorts of initiatives, mostly initiated by NGOs, the sector has increasingly paid attention to sustainability issues (Erich, 2012). Examples include Fair Trade, the MSC label for fish products or the production of organic products. Furthermore, Hollos et al. (2012) stated that customers and other stakeholders are inclined to punish companies, especially those selling branded products to the end consumer, that fail to comply with accepted sustainability standards. Moreover, due to the high pressure on prices and profit margins from retailers in the Netherlands (Grekova et al., 2014), cooperation within the chain seems necessary. Indeed, enhanced coordination between actors in the chain and the quality of their relationship are increasingly recognised as potential sources of competitiveness (Schiemann, 2007). Therefore, according to Grekova et al. (2014) and Erich (2012), the Dutch F\&B industry can be increasingly characterised by intense supply chain cooperation.

\subsection{Sample}

The sampling frame was compiled from the address file of Dutch F\&B companies from the Dutch Chamber of Commerce. A sample of 325 Dutch F\&B companies with at least 50 employees was selected. Consistent with the definition of small and medium-sized enterprises of the European Commission (EC, 2014), this research leaves out the small and micro-sized companies by only including companies with at least 50 employees. Small and micro-sized companies are outside the scope of this research. Grekova et al. (2014) showed that environmental sustainability practices and capabilities were less implemented and developed in small companies.

\footnotetext{
${ }^{1}$ Similar to the four levels of Baumgartner and Ebner (2010), Okongwu et al. (2013) and the Industrial Research Initiative (IRI, 2014) also identified four levels of maturity related to sustainability.
} 
After deletion of production locations and other double locations from the address file, 214 unique companies remained that together made up the sampling frame.

Each respondent in the sample was selected based on their job responsibilities, which had to be procurement or an equivalent function in which there was regular contact with suppliers. In an effort to increase the response rate, the research protocol started with an introductory telephone contact in which the respondents were asked for their cooperation and e-mail addresses. Subsequently, an e-mail with a personalised link to the online survey was sent. In order to enhance the response rate, respondents were offered a summary of the results. When respondents had not completed the survey after seven days, a reminder e-mail with a deadline for completing the survey was sent to encourage participation. After the data collection period of three weeks, 75 responses were received from the sample size of 214, resulting in a response rate of $35 \%$. After excluding 13 responses that were deemed unusable due to incompleteness, the effective response rate was $28.9 \%(62 / 214)$. The characteristics of the sample are provided in Table 1, showing the number of employees, the function of the respondents and the industry sector of the company within the food and beverages sector.

\subsection{Operationalisation of the variables}

A literature review was conducted to derive the variables that measure the theoretical constructs. All the items were measured using 7-point Likert scales ${ }^{2}$. In total, four general concepts were measured in the survey, namely the buyer-supplier relationship, the buyer capabilities, the supplier capabilities, and the maturity level of sustainable procurement.

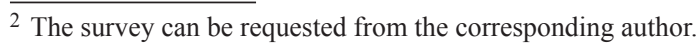

Table 1. Profile of respondents.

\begin{tabular}{|c|c|c|c|}
\hline & & $\mathbf{N}$ & Percentage \\
\hline \multirow[t]{5}{*}{ Number of employees } & $50-100$ & 11 & 18 \\
\hline & $100-500$ & 36 & 58 \\
\hline & $501-1000$ & 4 & 6 \\
\hline & $>1000$ & 11 & 18 \\
\hline & Total & 62 & 100 \\
\hline \multirow[t]{6}{*}{ Function respondents } & Presidents/vice presidents & 4 & 6 \\
\hline & Directors & 10 & 16 \\
\hline & Purchasing manager & 22 & 35 \\
\hline & Buyer & 22 & 35 \\
\hline & Other & 4 & 6 \\
\hline & Total & 62 & 100 \\
\hline \multirow[t]{8}{*}{ Industry sector } & Dairy & 4 & 6 \\
\hline & Meat & 8 & 13 \\
\hline & Fish and seafood & 3 & 5 \\
\hline & Fruit and vegetables & 6 & 10 \\
\hline & Bakery & 16 & 26 \\
\hline & Beverages & 6 & 10 \\
\hline & Other & 19 & 31 \\
\hline & Total & 62 & 100 \\
\hline
\end{tabular}


The concept buyer-supplier relationships is operationalised in terms of (1) power and dependency; (2) trust and commitment; (3) information exchange and communication; (4) geographical distance and (5) code of conduct. Power and dependency was measured using a three items construct to; assess the power of the supplier and a three items construct to assess the power of the buying company. Both these constructs have been adopted from Hoejmose et al. (2012). The concepts trust and commitment were measured using a three items construct on the degree of commitment present, which was adopted from Carter and Jennings (2002), and a three items construct on trust, which was adopted from Hoejmose et al. (2012). The information exchange and communication variable was measured via a four items construct that was adopted from Paulraj et al. (2008) to measure the inter-organisational communication and a three items construct adopted from Fawcett et al. (2007) on information technology. To measure the geographical distance, a three items construct was developed by the researchers themselves. Finally, in order to measure the concept code of conduct, a four and two items scale of Awaysheh and Klassen (2010) were used to measure respectively the existence of a code of conduct and the monitoring and evaluation activities present to control adherence to the code of conduct.

The buyer characteristics were the following: (1) supplier management; (2) the corporate culture; (3) stakeholder management; and (4) the level of know-how and expertise. Supplier management was measured using a five item scale based on Yu et al. (2014). The corporate culture was measured using a three items construct from Cousins et al. (2006) that measured top management support, another three items construct from Cousins et al. (2006) to measure cross-functional cooperation and finally, two items on the attitude of employees were adopted from Park and Stoel (2005). For the concept of stakeholder management, a three items construct was developed based on Crespin-Mazet and Dontenwill (2012). To measure the level of know-how and expertise, two items from Cousins et al. (2006) were used to assess the level of skills of purchasing employees on sustainability and two items were developed based on literature to assess the sustainability knowledge management.

The concept supplier characteristics covered (1) corporate culture; (2) know-how and expertise; and (3) access to resources. The corporate culture also included items on top management support, adopted from Cousins et al. (2006), and the attitude of employees (Park and Stoel, 2005). Furthermore, it comprised of a three-items construct adopted from Lee (2008) that measured the willingness to participate in the buyers' sustainability initiatives. The know-how and expertise was measured via a three items construct that was developed based on Lee (2008) and Rao (2002). Finally, the access to resources was also measured using a three-items construct that was based on Lee (2008) and Rao (2002).

Based on the maturity concept the level of integration of sustainability measurements in the company was included. For every sustainability dimension 4 aspects were selected. For economic sustainability: economic value distribution, sustainability reporting, knowledge management, innovation and technology (Amini and Bienstock, 2014; Baumgartner and Ebner, 2010; IRI, 2014; Okongwu et al., 2013; Van Marrewijk, 2005). For environmental sustainability: life cycle assessment, material and part purchasing, manufacturing impact, supplier management (adapted from IRI (2014) and Van Marrewijk (2005)). For social sustainability: health and safety, employee management, supplier management, corporate citizenship (adapted from Baumgartner and Ebner (2010); Carter and Jennings (2004); IRI (2014); Van Marrewijk (2005)). For every aspect of economic, environmental and social sustainability, a two items construct was developed. Each construct encompassed one item related to the organisational integration of that particular aspect and the other item measured the content integration of that sustainability aspect (see Supplementary Materials S1 for an overview of these items as included in the questionnaire). Moreover, as control variables questions were included on company performance and the presence of dedicated (sustainable) product lines. 


\section{Analysis}

\subsection{Principal component analysis}

In order to reduce the number of variables in the analysis, a principal component factor analysis (PCA) with oblimin rotation was conducted using SPSS 22 (IBM Corporation, Armonk, NY, USA). Since the survey was created based on theory, the PCA was driven by the earlier identified concepts of buyer capabilities, supplier capabilities and buyer-supplier relationships. Next, all three PCAs that were performed will be discussed. Subsequently, a description will be given of how the concept of maturity levels of sustainable procurement was divided into factors.

\subsection{Principal component analysis buyer-supplier relationships}

A PCA was conducted on the 28 items of the concept buyer-supplier relationship. Five components were retained explaining $73.19 \%$ of the variance combined. In Table 2 the factor loadings after rotation are presented (factor loadings over 0.4 appear in bold). The items that load on the same components suggest that component 1 represents loyalty in a relationship, component 2 the strictness of guidance in a relationship, component 3 joint dependency, component 4 the intensity of communication and component 5 the connectivity.

Table 2. Summary of principal component analysis for buyers-supplier relationships ( $\mathrm{N}=62)$.

\begin{tabular}{|c|c|c|c|c|c|}
\hline & 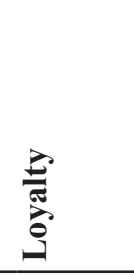 & 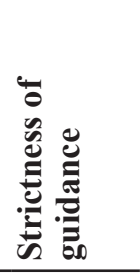 & 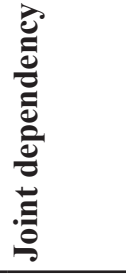 & 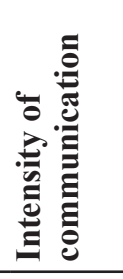 & 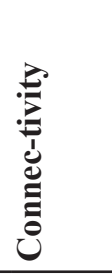 \\
\hline Promises made by suppliers are reliable. & 0.913 & 0.061 & 0.046 & -0.063 & 0.066 \\
\hline If problems arise. the suppliers are honest about the problems. & 0.871 & -0.104 & -0.012 & -0.157 & -0.225 \\
\hline Suppliers have been frank in dealing with us. & 0.756 & -0.037 & 0.026 & 0.182 & -0.006 \\
\hline We are committed to the relationship with these suppliers. & 0.645 & 0.046 & 0.051 & 0.287 & 0.022 \\
\hline Suppliers are monitored to ensure adherence to our code of conduct. & -0.100 & 0.918 & 0.007 & 0.072 & 0.056 \\
\hline $\begin{array}{l}\text { Supplier relationships are ended if suppliers do not adhere to our } \\
\text { code of conduct. }\end{array}$ & 0.119 & 0.836 & 0.037 & 0.062 & 0.068 \\
\hline $\begin{array}{l}\text { We have specific audit procedures to ensure that suppliers adhere to } \\
\text { our code of conduct. }\end{array}$ & 0.028 & 0.790 & -0.115 & 0.029 & -0.224 \\
\hline Purchasing has sustainable sourcing training programs. & -0.086 & 0.625 & 0.071 & -0.070 & -0.133 \\
\hline We account for a large proportion of these suppliers' total sales. & -0.028 & 0.019 & 0.881 & -0.028 & -0.034 \\
\hline The suppliers would find it difficult to replace us. & -0.038 & -0.181 & 0.812 & 0.224 & -0.242 \\
\hline We do not have a good alternative to these suppliers. & 0.048 & 0.211 & 0.731 & -0.283 & 0.171 \\
\hline We are important to these suppliers. & 0.384 & 0.002 & 0.584 & 0.208 & -0.024 \\
\hline We have frequent face-to-face communication. & -0.143 & 0.037 & -0.010 & 0.879 & -0.072 \\
\hline We inform each other about things that may affect the other. & 0.277 & 0.006 & 0.067 & 0.715 & 0.101 \\
\hline Suppliers are provided with any information that might help them. & 0.374 & 0.203 & -0.066 & 0.623 & -0.022 \\
\hline $\begin{array}{l}\text { Current information systems satisfy supply chain communication } \\
\text { requirements. }\end{array}$ & 0.206 & 0.132 & -0.058 & -0.133 & -0.811 \\
\hline Information systems are integrated throughout the supply chain. & -0.084 & 0.151 & 0.205 & 0.187 & $-\mathbf{0 . 7 4 0}$ \\
\hline Initial eigenvalues & 5.34 & 2.79 & 1.97 & 1.29 & 1.06 \\
\hline$\%$ of variance explained & 31.40 & 16.40 & 11.60 & 7.57 & 6.23 \\
\hline Cronbach's $\alpha$ & 0.86 & 0.83 & 0.80 & 0.78 & 0.71 \\
\hline
\end{tabular}


The internal consistency of the scales was assessed using Cronbach's $\alpha$ coefficients. The $\alpha$ coefficients all exceeded the threshold of 0.70 outlined by Nunnally (1978).

\subsection{Principal component analysis buyer characteristics}

A PCA was conducted on the 20 items of the concept buyer capabilities. Three components were retained explaining $60.02 \%$ of the variance combined. In Table 3 the factor loadings after rotation are presented (factor loadings over 0.4 appear in bold). The items that load on the same components suggest that component 1 represents the integration of sustainable procurement, component 2 the purchasing skills and component 3 the attitude of employees. The internal consistency of the scales was assessed using Cronbach's $\alpha$ coefficients. The Cronbach $\alpha$ coefficients were all well above the recommended threshold of 0.70 outlined by Nunnally (1978).

\subsection{Principal component analysis supplier characteristics}

A PCA was conducted on the 13 items of the concept supplier capabilities. Three components were retained explaining $67.90 \%$ of the variance combined. In Table 4 the factor loadings after rotation are presented (factor loadings over 0.4 appear in bold). The items that load on the same components suggest that component 1 represents the supplier attitude, component 2 the access to resources from the buying company and component 3 the supplier sustainable resources deployment. The internal consistency of the scales was assessed using

Table 3. Summary of principal component analysis for buyer characteristics $(\mathrm{N}=62)$.

\begin{tabular}{|c|c|c|c|}
\hline & 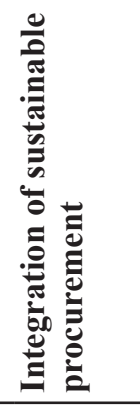 & 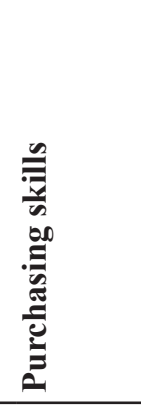 & 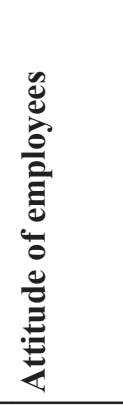 \\
\hline Sustainability is considered a vital part of our corporate strategy. & 0.947 & -0.014 & -0.085 \\
\hline My company stimulates working together with suppliers for sustainability. & 0.903 & 0.023 & -0.152 \\
\hline My company cooperates with suppliers for achieving sustainability objectives together. & 0.866 & 0.058 & -0.105 \\
\hline Top management supports our efforts to improve sustainability. & 0.783 & -0.120 & 0.187 \\
\hline Design specifications with sustainability requirements are provided to suppliers. & 0.739 & 0.212 & -0.138 \\
\hline Top management values purchasing views on sustainable procurement. & 0.725 & -0.027 & 0.151 \\
\hline Social sustainability risks are integrated in purchasing decisions. & 0.724 & 0.060 & 0.213 \\
\hline Environmental sustainability risks are integrated in purchasing decisions. & 0.653 & 0.071 & 0.185 \\
\hline Purchasing actively identifies relevant stakeholders. & 0.053 & 0.882 & -0.239 \\
\hline Stakeholder input is integrated in purchasing processes. & 0.187 & 0.815 & -0.322 \\
\hline My company ensures training needs of employees are identified and acted upon. & -0.220 & 0.754 & 0.386 \\
\hline My company stimulates working in cross-functional teams. & 0.010 & 0.724 & 0.156 \\
\hline Purchasing has the skills to interpret changes in the supplier market. & 0.069 & 0.693 & -0.032 \\
\hline Purchasing participates in product and process design. & 0.137 & 0.603 & 0.237 \\
\hline My colleagues' business decisions are highly socially responsible. & 0.369 & 0.089 & 0.689 \\
\hline My colleagues are highly ethical and socially responsible. & 0.370 & 0.122 & 0.617 \\
\hline Initial eigenvalues & 7.59 & 2.24 & 1.22 \\
\hline$\%$ of variance explained & 47.44 & 13.99 & 7.59 \\
\hline Cronbach's $\alpha$ & 0.93 & 0.86 & 0.79 \\
\hline
\end{tabular}


Table 4. Summary of principal component analysis for supplier characteristics $(\mathrm{N}=62)$.

\begin{tabular}{|c|c|c|c|}
\hline & 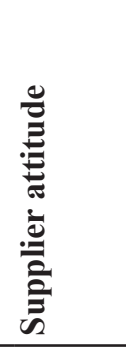 & 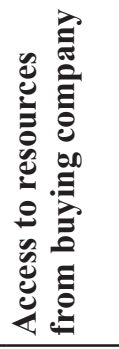 & 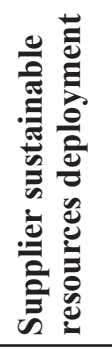 \\
\hline The suppliers' top management values its employees' views on sustainability. & 0.879 & -0.028 & -0.034 \\
\hline The suppliers expect benefits from the sustainability initiatives. & 0.865 & 0.210 & -0.070 \\
\hline The suppliers' employees behave highly ethical and socially responsible. & 0.767 & -0.042 & -0.113 \\
\hline The suppliers are willing to participate in our sustainability initiatives. & 0.705 & 0.027 & 0.232 \\
\hline The suppliers' top management wants to improve sustainability. & 0.698 & -0.096 & 0.234 \\
\hline The suppliers are aware of our sustainability initiatives. & 0.426 & 0.261 & 0.317 \\
\hline My company provides training/education to the supplier's. & 0.047 & 0.896 & -0.019 \\
\hline My company arranges funds to help suppliers increase their sustainability. & 0.020 & 0.886 & 0.013 \\
\hline Suppliers engage in inter-firm sustainability knowledge transfer. & -0.100 & 0.236 & 0.825 \\
\hline Suppliers have the internal resources to invest in our sustainability requirements. & 0.035 & -0.125 & 0.764 \\
\hline Suppliers have the knowledge and expertise required to act upon sustainability. & 0.291 & -0.209 & 0.600 \\
\hline Initial eigenvalues & 4.67 & 1.74 & 1.06 \\
\hline$\%$ of variance explained & 42.44 & 15.85 & 9.61 \\
\hline Cronbach's $\alpha$ & 0.87 & 0.80 & 0.67 \\
\hline
\end{tabular}

Cronbach's $\alpha$ coefficients. The $\alpha$ coefficients for the supplier corporate culture $(\alpha=0.87)$ and access to resources from the buying company $(\alpha=0.80)$ were well above the lower limits of acceptability of 0.70 outlined by Nunnally (1978). The $\alpha$ coefficients for supplier internal resources reached a respectable 0.67.

\subsection{Integration of sustainable procurement}

Unlike the other concepts, no principal component analysis was run on the 24 items (see annex) of the concept integration of sustainable procurement. Since a PCA could relate the 24 items to different dimensions of sustainability than intended in this research (i.e. economic, social and environmental), it was chosen not to perform a PCA. Instead, based on the strong conceptual motivations of the maturity model, the items belonging to the economic, social and environmental aspects respectively were added to create three factors. These factors each comprise eight items and represent the economic, social and environmental sustainability integration level of the purchasing department. The internal consistency of the scales was assessed using Cronbach's $\alpha$ coefficients. The $\alpha$ coefficients for the economic aspects $(\alpha=0.87)$, social aspects $(\alpha=0.87)$ and environmental aspects $(\alpha=0.91)$ were all well above the threshold of 0.70 outlined by Nunnally (1978).

\subsection{Cluster analysis}

The previous section analysed the key characteristics reflecting the constructs buyer-supplier relationships, buyer capabilities, supplier capabilities and sustainable procurement maturity level. As the objective of this study was to gain insight into procurement practices and sustainable procurement, the next step in the analysis was to cluster the companies $(\mathrm{N}=62)$ based on the 14 created factors. According to Meyers et al. (2012), cluster analysis is often used as an exploratory approach. Moreover, due to the small sample size cluster analysis is an appropriate choice, as cluster analysis does not have very strong assumptions that have to be met in order to properly interpret the results (Meyers et al., 2012). 
The cluster analysis structured the procurement practices based on the buyer capabilities, supplier capabilities, the buyer-supplier relationship and the integration levels of sustainable procurement. In this way, an overview is created of typologies of companies, based on these four concepts. To conduct the cluster analysis, a hierarchical agglomerative technique with Ward's method and the squared Euclidean distance measure was used. In conducting the cluster analysis all values were standardised to $\mathrm{Z}$ scores, because the values of the variables created via the PCAs were on different scales than the values of the variables that were created via adding (i.e. the sustainability maturity variables).

\section{Results}

Table 5 provides the agglomeration coefficients. The number of clusters is determined based on where the distance coefficients make a larger change (Burns and Burns, 2009). In this case, from 48.73 on there are relatively large changes. Based on this criterion, a four-cluster solution was selected as most appropriate.

\subsection{Cluster interpretation}

The interpretation stage involves assigning each of the four identified clusters a name or label that accurately describes the nature of that cluster (Cousins et al., 2006). Table 6 shows the final four-cluster solution. It describes each cluster based on the central concepts of this research: supplier capabilities, buyer capabilities, the buyer-supplier relationship and sustainability performance that were found per cluster.

In order to interpret the clusters better, other, possible explanatory questions from the survey were compared with the cluster groups via comparing means and crosstab analysis in SPSS. Next, the performance of the clusters was assessed using the performance indicators from the survey. The highest scoring cluster on sustainable procurement performance also has the highest cost reductions, largest growth in market share and higher profits due to its sustainability activities. The second highest scoring cluster has the second best improvements on these aspects, the third and the worst scoring cluster show no improvements on these performance indicators. The same distribution holds for the cluster scorings on the integration of the three sustainability aspects and their own assessment of their sustainability. The results furthermore showed that in the highest scoring cluster in terms of sustainable procurement performance almost all companies (11 vs 2) had a special product line focussed on high sustainability levels. For the second best cluster this was more equally divided ( 9 vs 14), whereas the two lowest scoring clusters had significantly more companies without these special sustainability focussed product lines ( 2 vs 18 and 1 vs 5). Finally, the results showed that the number of employees cannot explain the cluster distribution.

As has been mentioned before, this research focusses on the incorporation of the Triple Bottom Line, in which all three sustainability aspects are equally important. Table 7 shows the mean and standard deviation per cluster. Except for the third cluster, the three sustainability aspects are quite equally integrated in the other three clusters. Additionally, Table 7 shows that for all clusters the environmental sustainability aspect of sustainable procurement is implemented to a lesser extent than the economic and social sustainability aspects.

Table 5. Reformed agglomeration schedule.

\begin{tabular}{llll}
\hline Clusters & Agglomeration last step & Coefficients this step & Change \\
\hline 2 & 854.00 & 631.25 & 222.75 \\
3 & 631.25 & 570.12 & 61.13 \\
4 & 570.12 & 521.39 & 48.73 \\
5 & 521.39 & 480.02 & 41.37 \\
6 & 480.02 & 448.55 & 31.48 \\
7 & 448.55 & 418.69 & 29.86 \\
8 & 418.69 & 393.05 & 25.65 \\
\hline
\end{tabular}


Table 6. Final clusters mean and standard deviation.

\begin{tabular}{|c|c|c|c|c|c|}
\hline & $\begin{array}{l}\text { Cluster } 1 \\
(\mathbf{N}=\mathbf{2 0}) \\
\text { Mean (SD) }\end{array}$ & $\begin{array}{l}\text { Cluster } 2 \\
(\mathrm{~N}=13) \\
\text { Mean (SD) }\end{array}$ & $\begin{array}{l}\text { Cluster } 3 \\
(\mathrm{~N}=6) \\
\text { Mean (SD) }\end{array}$ & $\begin{array}{l}\text { Cluster } 4 \\
(\mathrm{~N}=23) \\
\text { Mean (SD) }\end{array}$ & $\mathbf{F}$ \\
\hline Supplier attitude & $-0.92(0.87)$ & $0.61(0.71)$ & $0.16(1.12)$ & $0.41(0.63)$ & $\begin{array}{l}\mathrm{F}=13.990 \\
P<0.05\end{array}$ \\
\hline Access to resources from buying company & $-0.32(1.02)$ & $0.44(0.99)$ & $-0.93(0.37)$ & $0.27(0.89)$ & $\begin{array}{l}\mathrm{F}=4.400 \\
P<0.05\end{array}$ \\
\hline Supplier sustainable resources deployment & $-0.88(0.82)$ & $0.62(0.83)$ & $1.02(0.73)$ & $0.14(0.68)$ & $\begin{array}{l}\mathrm{F}=15.540 \\
P<0.05\end{array}$ \\
\hline Integration on sustainable procurement & $-0.88(0.64)$ & $1.00(0.32)$ & $-1.09(1.03)$ & $0.48(0.52)$ & $\begin{array}{l}\mathrm{F}=39.490 \\
P<0.05\end{array}$ \\
\hline Purchasing skills & $-0.90(1.08)$ & $0.73(0.44)$ & $0.91(0.30)$ & $0.13(0.59)$ & $\begin{array}{l}\mathrm{F}=17.169 \\
P<0.05\end{array}$ \\
\hline Attitude of employees & $-0.06(0.94)$ & $0.41(0.86)$ & $-1.06(0.79)$ & $0.09(1.02)$ & $\begin{array}{l}\mathrm{F}=3.446 \\
P<0.05\end{array}$ \\
\hline Loyalty & $-0.55(1.21)$ & $0.59(0.79)$ & $0.14(0.80)$ & $0.10(0.73)$ & $\begin{array}{l}\mathrm{F}=4.228 \\
P<0.05\end{array}$ \\
\hline Strictness of guidance & $-0.39(0.95)$ & $1.07(0.67)$ & $-0.88(1.01)$ & $-0.04(0.70)$ & $\begin{array}{l}\mathrm{F}=11.390 \\
P<0.05\end{array}$ \\
\hline Joint dependency & $-0.21(0.86)$ & $0.30(1.01)$ & $-1.09(0.67)$ & $0.30(0.98)$ & $\begin{array}{l}\mathrm{F}=4.345 \\
P<0.05\end{array}$ \\
\hline Intensity of communication & $-0.77(0.91)$ & $0.56(0.44)$ & $0.34(0.38)$ & $0.26(1.05)$ & $\begin{array}{l}\mathrm{F}=8.105 \\
P<0.05\end{array}$ \\
\hline Connectivity & $0.34(1.14)$ & $-0.81(0.72)$ & $0.96(0.56)$ & $-0.08(0.73)$ & $\begin{array}{l}\mathrm{F}=7.250 \\
P<0.05\end{array}$ \\
\hline Economic sustainability & $26.05(7.62)$ & $44.46(4.22)$ & $27.67(5.24)$ & $34.74(5.95)$ & $\begin{array}{l}\mathrm{F}=25.20 \\
P<0.05\end{array}$ \\
\hline Environmental sustainability & $21.50(4.51)$ & $40.85(6.94)$ & $14.17(3.19)$ & $29.70(7.30)$ & $\begin{array}{l}\mathrm{F}=37.14 \\
P<0.05\end{array}$ \\
\hline Social sustainability & $25.95(6.30)$ & $42.39(5.11)$ & $23.00(6.75)$ & $36.26(6.16)$ & $\begin{array}{l}\mathrm{F}=27.10 \\
P<0.05\end{array}$ \\
\hline
\end{tabular}

Table 7. Mean and standard deviation of sustainable procurement performance.

\begin{tabular}{lcccc}
\hline & $\begin{array}{l}\text { Cluster } \mathbf{1} \\
(\mathbf{N}=\mathbf{2 0})\end{array}$ & $\begin{array}{l}\text { Cluster 2 } \\
(\mathbf{N}=\mathbf{1 3})\end{array}$ & $\begin{array}{l}\text { Cluster 3 } \\
\mathbf{( N = 6 )}\end{array}$ & $\begin{array}{l}\text { Cluster 4 } \\
\mathbf{( N = 2 3 )}\end{array}$ \\
\hline Economic sustainability & 26.05 & 44.46 & 27.67 & 34.74 \\
Environmental sustainability & 21.50 & 40.85 & 14.17 & 29.70 \\
Social sustainability & 25.95 & 42.38 & 23.00 & 36.26 \\
Mean & 24.50 & 42.56 & 21.61 & 33.57 \\
SD & 2.60 & 1.81 & 6.86 & 3.44 \\
\hline
\end{tabular}

The scores on each of these three factors were combined to form a measure of sustainable procurement performance. This was done by taking the average of the scores on the three aspects for each cluster. In the analysis of the results this average is used in the graph to represent the sustainable procurement performance. 


\subsection{Describing the clusters: finding patterns of sustainable procurement in a buyer-supplier relationship setting}

As mentioned previously, part of the interpretation stage involves assigning the clusters a name or label that accurately describes the nature of that cluster (Cousins et al., 2006). The rationale for each of these names will be given next. The first cluster is labelled 'market relationship'. This cluster represents 20 companies or $32.3 \%$ of the sampled population. The practices in this cluster strongly resemble a market type of relationship, meaning that the buyer and the supplier are not committed to each other or the relationship, the information exchange is relatively low and there is little coordination needed (Gereffi et al., 2005). This type of arm'slength market relationship is comparable to what is found in cluster 1 . The companies do not invest in each other, communication is brought to a minimum and there is no loyalty towards each other. Moreover, sustainability is not a goal for these companies, which means the complexity will be low and prices are the most important, as is also the case for market relationships (Gereffi et al., 2005).

The second cluster is termed 'sustainability leader'. This cluster represents 13 companies or $21 \%$ of the sampled population. This cluster scores significantly better than the other clusters on the maturity level of sustainable procurement. Moreover, the cluster scores by far the highest on strictness of guidance, indicating that there is a strict code of conduct and that there are strict rules to follow. This resembles a strong leadership with tight control to ensure sustainability. Since both the buyer and the supplier want to be sustainable and there is a high degree of loyalty and a high intensity of communication, the highest sustainable performance is reached in this cluster. Surprisingly, the (systems) connectivity of cluster 2 is by far the lowest compared to the other clusters.

The third cluster is termed 'one-sided sustainability'. This cluster represents 6 companies or $9.7 \%$ of the sample. The 'one-sided sustainability' cluster reflects a buyer-supplier relationship in which the supplier is capable and willing to invest in sustainability, but where the buying company is not interested in sustainability. This cluster scores lowest on the performance level of sustainable procurement reached, but remarkably, the cluster scores by far the highest on connectivity. The very low joint dependency and the very low strictness of guidance also indicate that the buying company is reluctant to engage in sustainability, thereby resembling the one-sidedness of the sustainability performance that is reached.

Finally, cluster 4 is labelled 'inconclusive sustainability'. This cluster comprises of 23 companies or $37 \%$ of the sample. The cluster scores second highest for the performance level of sustainable procurement. Although both the buyer and the supplier care for sustainability, the supplier does not have the needed resources and the buying company does not do as much as it could. For example, the integration of sustainable procurement is good, but could be a lot higher, and the resources they provide to their suppliers could also be higher. Therefore, this cluster is termed 'inconclusive sustainability', as both parties do work on sustainability, but not to the extent that the highest sustainability performance is reached. Table 8 summarises the findings.

\subsection{Division of Food \& Beverage sectors over clusters}

From Figure 1 it becomes clear that no real pattern can be found in the distribution of sectors within the Dutch F\&B industry over the clusters ${ }^{3}$. It can be seen that all four dairy companies are in the two highest scoring clusters in terms of sustainability performance. Furthermore, most bakeries (13 out of 16) are placed in the middle two clusters in terms of sustainability performance. However, the main result that can be found in Figure 1 is that sustainability performance does not seem to be constrained to sub-sectors within the Dutch F\&B industry, as the sub-sectors are very distributed over the clusters.

\footnotetext{
${ }^{3}$ We also made a breakdown of cluster members by company size. This didn't provide us with new insights.
} 
Table 8. Description of the clusters.

\begin{tabular}{|c|c|c|c|c|}
\hline & $\begin{array}{l}\text { Cluster } 1 \\
\text { (market relationship) } \\
(\mathrm{N}=20)\end{array}$ & $\begin{array}{l}\text { Cluster } 2 \\
\text { (sustainability leader) } \\
(\mathrm{N}=13)\end{array}$ & $\begin{array}{l}\text { Cluster } 3 \\
\text { (one-sided sustainability) } \\
(\mathrm{N}=6)\end{array}$ & $\begin{array}{l}\text { Cluster } 4 \\
\text { (inconclusive sustainability) } \\
(\mathbf{N}=23)\end{array}$ \\
\hline $\begin{array}{l}\text { Supplier } \\
\text { characteristics }\end{array}$ & $\begin{array}{l}\text { - Suppliers are characterised by a } \\
\text { very negative attitude towards } \\
\text { sustainability. } \\
\text { - Suppliers do not have internal } \\
\text { resources or access to resources } \\
\text { from the buying company to invest } \\
\text { in sustainability. }\end{array}$ & $\begin{array}{l}\text { - The suppliers are characterised by } \\
\text { a very positive attitude towards } \\
\text { sustainability. } \\
\text { - Suppliers have good access } \\
\text { to resources from the buying } \\
\text { company, but also have sufficient } \\
\text { resources of their own to invest in } \\
\text { sustainability. }\end{array}$ & $\begin{array}{l}\text { - The suppliers are characterised by } \\
\text { a very high degree of sustainable } \\
\text { resources to deploy, whilst } \\
\text { simultaneously no degree of access } \\
\text { to resources from the buying } \\
\text { company at all. } \\
\text { - The suppliers are willing to invest } \\
\text { in sustainability. }\end{array}$ & $\begin{array}{l}\text { - The suppliers are characterised } \\
\text { by their positive attitude towards } \\
\text { sustainability. } \\
\text { - Suppliers have limited access to } \\
\text { resources from the buying company } \\
\text { and they only have limited } \\
\text { resources available themselves. }\end{array}$ \\
\hline $\begin{array}{l}\text { Buyer } \\
\text { characteristics }\end{array}$ & $\begin{array}{l}\text { - Buyers are characterised by } \\
\text { very low purchasing skills and } \\
\text { a low integration of sustainable } \\
\text { procurement. } \\
\text { - Employees don't really have } \\
\text { anything against sustainability, but } \\
\text { they are not enthusiastic about it. }\end{array}$ & $\begin{array}{l}\text { - Buyers are characterised by a } \\
\text { very high level of integration } \\
\text { of sustainable procurement in } \\
\text { the company and a positive } \\
\text { attitude of the employees towards } \\
\text { sustainability. } \\
\text { - Buyers have very good purchasing } \\
\text { skills. }\end{array}$ & $\begin{array}{l}\text { - The buyers are characterised } \\
\text { by no integration of sustainable } \\
\text { procurement whatsoever and a } \\
\text { very negative attitude towards } \\
\text { sustainability. } \\
\text { - The buyers do have very high } \\
\text { purchasing skills. }\end{array}$ & $\begin{array}{l}\text { - The buyers are characterised by } \\
\text { a good integration of sustainable } \\
\text { procurement, but only average } \\
\text { purchasing skills. } \\
\text { - The employees are not against } \\
\text { sustainable procurement, but are } \\
\text { only very slightly positive about it. }\end{array}$ \\
\hline $\begin{array}{l}\text { Buyer-supplier } \\
\text { relationship }\end{array}$ & $\begin{array}{l}\text { - The relationship is characterised } \\
\text { by a very low intensity of } \\
\text { communication and the absence of } \\
\text { loyalty. } \\
\text { - There is no joint dependency and } \\
\text { also no strictness of guidance. } \\
\text { - Remarkably, connectivity is quite } \\
\text { alright. }\end{array}$ & $\begin{array}{l}\text { - The relationship is characterised by } \\
\text { the very high degree of strictness } \\
\text { of guidance, combined with a very } \\
\text { low degree of connectivity. } \\
\text { - Both the intensity of } \\
\text { communication and the loyalty } \\
\text { towards each other is high, but they } \\
\text { are only to some degree dependent } \\
\text { on each other. }\end{array}$ & $\begin{array}{l}\text { - The relationship is characterised by } \\
\text { a very high degree of connectivity } \\
\text { and quite a lot of communication. } \\
\text { - The relationship is also } \\
\text { characterised by a small degree } \\
\text { of loyalty, but no strictness of } \\
\text { guidance or joint dependency at all. }\end{array}$ & $\begin{array}{l}\text { - The relationship is characterised by } \\
\text { a small degree of loyalty and joint } \\
\text { dependency. } \\
\text { - Connectivity is limited, but } \\
\text { there is a reasonable intensity of } \\
\text { communication and there is some } \\
\text { degree of strictness of guidance. }\end{array}$ \\
\hline Performance & $\begin{array}{l}\text { - The buying companies did not } \\
\text { experience cost reductions, increase } \\
\text { in market share or higher profits } \\
\text { as a result of their sustainability } \\
\text { activities. }\end{array}$ & $\begin{array}{l}\text { - The buying companies experienced } \\
\text { quite a lot of cost reductions and } \\
\text { also a good increase in market } \\
\text { share and higher profits due to their } \\
\text { sustainability activities. }\end{array}$ & $\begin{array}{l}\text { - The buying companies did not } \\
\text { create any cost reductions, larger } \\
\text { market shares or higher profits } \\
\text { as a result of their sustainability } \\
\text { activities at all. }\end{array}$ & $\begin{array}{l}\text { - The buying companies experienced } \\
\text { quite some cost reductions, created } \\
\text { a larger market share and also saw } \\
\text { their profit increase a bit due to } \\
\text { their sustainability activities. }\end{array}$ \\
\hline
\end{tabular}




\section{Conclusions}

\subsection{Buyer-supplier relationships}

The results of the empirical research have provided some valuable insights into the relationship between aspects of buyer-supplier relationships and sustainable procurement performance. First of all, the analysis showed that loyalty, which encompasses aspects of trust and commitment, is positively related ${ }^{4}$ to sustainable procurement performance. Additionally, the results showed that joint dependency was positively related to sustainable procurement performance. In the cases where both the supplier and the buyer were dependent on each other, sustainable procurement performance was higher than when there was no joint dependency. Thus, this research does not support scholars who advocate the use of power to force suppliers to act sustainable. However, the results do show an important role for the strictness of guidance in the buyersupplier relationship. The positive relationship between strictness of guidance and sustainable procurement performance indicates that codes of conduct, rules and audit procedures have a positive influence on the level of sustainable procurement. Finally, the analysis showed two interesting results. The intensity of communication, which includes aspects of face-to-face communication and willingness to share information, has a positive relationship with sustainable procurement performance. This confirms the expectations from the literature study. However, connectivity, which includes aspects on the linkage and integration of information systems, has a negative relationship with sustainable procurement performance. This does not necessarily imply that connectivity has a negative influence on sustainable procurement, but it does indicate that connectivity is not a prerequisite for sustainable procurement.

\subsection{Characteristics of the buying company}

From the analysis it became clear that the integration of sustainable procurement in business processes is an important capability needed. This includes the integration of sustainability criteria in the purchasing process, sustainable supplier development activities and top management support. Additionally, purchasing skills

\footnotetext{
${ }^{4}$ The relationships described in this section are only indicative, i.e. not statistically significant, and deduced from the characteristics of the clusters.
}

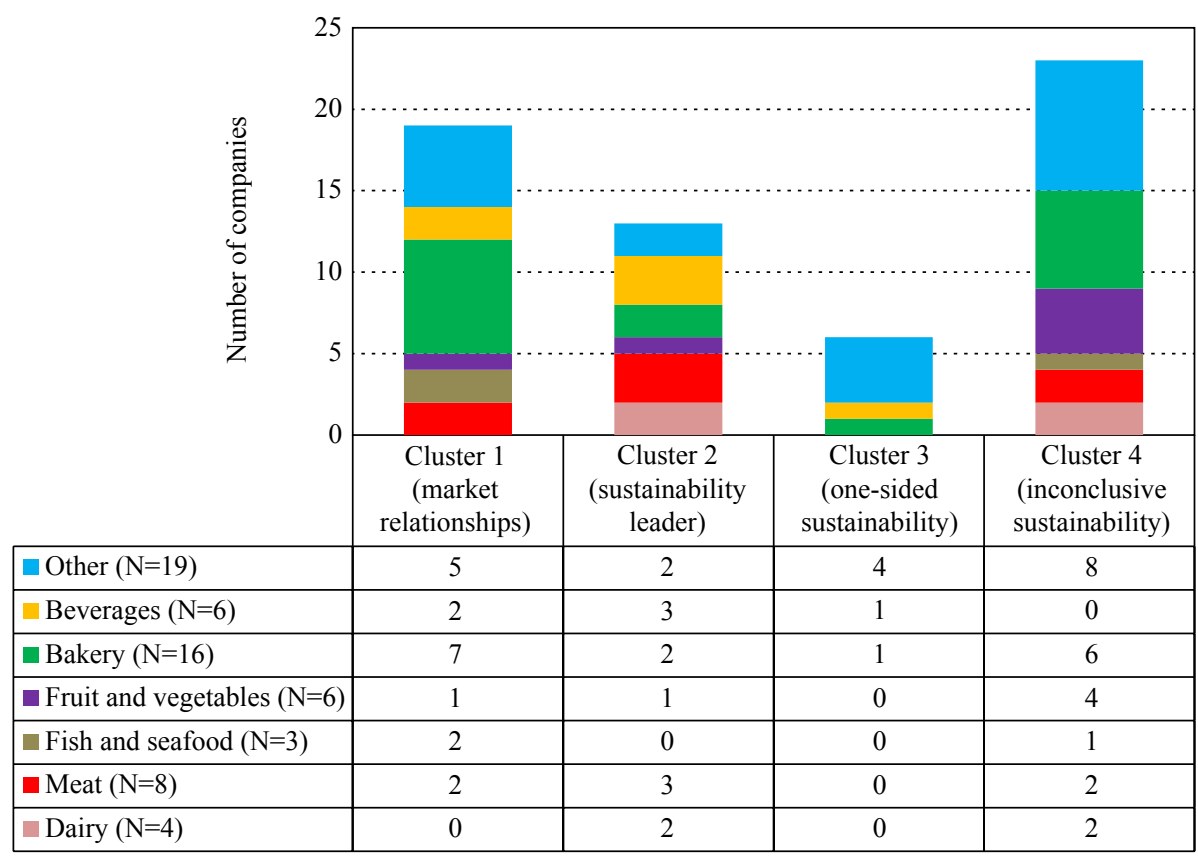

Figure 1. Cluster members per sector in the Dutch food and beverages industry. 
are also positively related to sustainable procurement performance. Purchasing skills include aspects like stakeholder management, cross-functional cooperation and knowledge and skills of the purchasing personnel. Finally, the results showed the positive relation between attitude of the employees and sustainable procurement performance. This means that ethical and socially responsible personnel supports higher performance levels of sustainable procurement.

\subsection{Characteristics of the supplier}

The analysis showed as well that access to resources from the buying company is positively related to sustainable procurement performance. This means that when suppliers have access to funds and training or education from the buyer, this positively influences the maturity levels of sustainable procurement that can be reached. Additionally, the results present a positive relation between supplier sustainable resources deployment and sustainable procurement performance. This includes internal resources and knowledge available at the supplier and supplier's engagement in inter-firm sustainability knowledge transfer activities. Finally, the results showed the influence of supplier attitude on sustainable procurement. This means the higher the top management support, the willingness to engage in sustainability initiatives and the ethical and social responsibility of employees, the higher the performance level of sustainable procurement.

\section{Discussion}

\subsection{Theoretical implications}

This section will discuss the findings from this empirical research against the background of findings of other research along with a theoretical reflection on the results. First of all, the general findings of this empirical research are in line with those stemming from the earlier mentioned study of Pagell et al. (2010). Similar to the results of their study, this research has shown that more cooperative forms of buyer-supplier relationships, in which the buyer provides the supplier with the needed resources, contribute to ensure sustainability. Pagell et al. (2010) changed the dominant approach to purchasing portfolio models, because they found economically very viable companies that were not making decisions in the manner suggested by Kraljic (1983). Indeed, one of the most contradictory results from this research and the study of Pagell et al. (2010) compared to the traditional purchasing portfolios, is the purposeful increase of supply risk. Similar to the results of Pagell et al. (2010), this research shows that companies that invest in sustainability purposefully increase asset specificity through intense communication, providing resources to suppliers and creating strict guidance, thereby increasing the supply risk as defined by Kraljic (1983).

A second interesting reflection on this study includes the question whether a company's position in the supply chain has an effect on its performance level of sustainable procurement. Whilst asking the respondents to cooperate in this research, one of the respondents stated that they did not take part in any sustainability activities, because they were not selling to end-consumers. This suggests that the level of sustainable procurement may depend on the company's position in the supply chain. Indeed, Hoejmose et al. (2012) showed that green practices in business to business (B2B) supply chains were considerably underdeveloped compared to business to consumer (B2C) supply chains. González-Benito and González-Benito (2006) also stated that companies further down the chain, thus not directly visible to consumers, are more reactive in their approach to sustainability. This could be caused by what Hollos et al. (2012) stated, that particular consumers and other stakeholders are inclined to punish companies, especially those selling branded products to the end consumer, if they fail to comply with accepted sustainability standards. Although this research did not take into account the company's position in the supply chain, it could be an interesting addition for future research as it could explain some of the differences found between the clusters in this research.

Finally, another relevant theoretical reflection concerns connectivity. A surprising outcome of the empirical research was that connectivity was negatively correlated to sustainable procurement performance. The results show that the best performing companies in terms of sustainability, had no connectivity whatsoever 
whilst the worst performing companies had a very high connectivity. Theoretically, it would be expected that connectivity should be high, since the buying company would need to know what the supplier is doing regarding sustainability. Following this assumption, information systems would be integrated enabling easy and quick information exchange about sustainability activities. Nevertheless, the results from the empirical research proved otherwise. As Fawcett et al. (2007) stated, information sharing and communication are too often mistaken for being a technology issue. Although information technology provides opportunities for enhanced communication and collaboration (Makkonen and Vuori, 2014), a company's willingness to share information ultimately determines the extent and quality of communication (Fawcett et al., 2007). As the intensity of communication did appear to be positively related to sustainable procurement performance, it seems that the willingness to share information is indeed more supportive for sustainable procurement than connectivity. The 'sustainability leader' cluster confirms this, as it shows the highest intensity of communication and, at the same time, the lowest connectivity of all clusters. However, it should be noted that as information technology enables a free flow of information among companies (Spekman and Carraway, 2006), this could facilitate the enhancement of communication and could thereby potentially increase sustainable procurement performance even further.

\subsection{Recommendations}

This final section discusses recommendations for future research and practitioners. The first recommendation for future research would be to investigate factors that could stimulate a feeling of joint dependency, as this was found to be very important in reaching sustainable procurement. Secondly, an interesting reflection on this research involved the question whether a company's position in the supply chain has an effect on the integration level of sustainable procurement that is reached. Since business to business and business to consumer markets differ on quite some aspects, it would add to the current knowledge to investigate whether this is also the case for buyer-supplier relationships and how they facilitate sustainable procurement. Thirdly, the influence of geographical distance on buyer-supplier relationships could not be determined in this research. As it has the potential to influence the relationship and sustainable procurement, it would be relevant to know if and how geographical distance affects these concepts. Therefore, future research could be focussed in that direction. Fourthly, the nature of the identified clusters, also against the theoretical background of maturity levels, raises questions to whether transition from the one to the other cluster occurs and can occur 'smoothly', and if companies can skip stages. These questions warrant future research. Overall, since theory on the effect of buyer-supplier relationships on sustainable procurement performance is relatively under developed, more research is needed to confirm the results found in this study. In this light, it would also be relevant to perform a similar study in a different business environment, to check whether these results are bounded to the Dutch F\&B industry or whether they also apply in other sectors, in other countries.

Finally, some recommendations to practitioners can be made. This research has shown that the integration of sustainable procurement throughout the company is necessary to achieve a high sustainable procurement performance. This involves integrating sustainability criteria in the purchasing process, sustainable supplier development activities and top management support. Furthermore, as a buying company one should have good purchasing skills, including stakeholder management, cross-functional cooperation and sufficient sustainability related knowledge and skills of the purchasing personnel. Additionally, it is important that the employees have a positive attitude towards sustainability. In the buyer-supplier relationship, special attention should be paid to creating a feeling of loyalty encompassing trust and commitment. Not only do trust and commitment increase sustainable procurement performance, they also increase the intensity of communication, which in turn is also important for reaching high sustainable procurement performance. Recommendations are directly aligned with these findings. Furthermore, it is advised to invest in strict guidance through codes of conduct and monitoring and control activities. Finally, this research has shown that a feeling of joint dependency positively influences sustainable procurement performance. It is therefore recommended to also create a feeling of joint dependency in the buyer-supplier relationship. 


\section{Supplementary material}

Supplementary material can be found online at https://doi.org/10.22434/IFAMR2017.0059.

Materials S1. Survey.

\section{References}

Ageron, B., A. Gunasekaran and A. Spalanzani. 2012. Sustainable supply management: an empirical study. International Journal of Production Economics 140(1): 168-182.

Amaeshi, K.M., O.K. Spalanzani and P. Nnodim. 2008. Corporate social responsibility in supply chains of global brands: a boundaryless responsibility? Clarifications, exceptions and implications. Journal of Business Ethics 81(1): 223-234.

Amini, M. and C.C. Bienstock. 2014. Corporate sustainability: an integrative definition and framework to evaluate corporate practice and guide academic research. Journal of Cleaner Production 76(1): 12-19.

Andersen, M. and T. Skjoett-Larsen. 2009. Corporate social responsibility in global supply chains. Supply Chain Management 14(2): 75-86.

Awaysheh, A. and R.D. Klassen. 2010. The impact of supply chain structure on the use of supplier socially responsible practices. International Journal of Operations \& Production Management 30(12): 1246-1268.

Baumgartner, R.J. and D. Ebner. 2010. Corporate sustainability strategies: sustainability profiles and maturity levels. Sustainable Development 18): 76-89.

Beske, P., A. Land and S. Seuring. 2014. Sustainable supply chain management practices and dynamic capabilities in the food industry: a critical analysis of the literature. International Journal of Production Economics 152: 131-143.

Beske, P. and S. Seuring. 2014. Putting sustainability into supply chain management. Supply Chain Management 19(3): 322-331.

Blome, C., D. Hollos and A. Paulraj. 2014. Green procurement and green supplier development: antecedents and effects on supplier performance. International Journal of Production Research 52(1): 32-49.

Boks, C. 2006. The soft side of ecodesign. Journal of Cleaner Production 14(15/16): 1346-1356.

Brammer, S. and H. Walker. 2011. Sustainable procurement in the public sector: an international comparative study. International Journal of Operations and Production Management 31(4): 452-476.

Bruno, T. C.J. Gelderman, W. Lambrechts and J. Semeijn. 2018. The promise of best value procurement: governance and (in)stability of specifications within an innovative biogas project. Journal of Cleaner Production 172: 1465-1475.

Burns, R.P. and R.A. Burns. 2009. Business research methods and statistics using SPSS. Sage Publications, London, UK.

Caniëls, M.C.J., M.H. Gehrsitz and J. Semeijn. 2013. Participation of suppliers in greening supply chains: an empirical analysis of German automotive suppliers. Journal of Purchasing and Supply Management 19(3): 134-143.

Caniëls, M.C.J. and C.J. Gelderman. 2007. Power and interdependence in buyer supplier relationships: a purchasing portfolio approach. Industrial Marketing Management 36(2): 219-229.

Carter, C.R. and P.L. Easton. 2011. Sustainable supply chain management: evolution and future directions. International Journal of Physical Distribution and Logistics Management 41(1): 46-62.

Carter, C.R. and M.M. Jennings. 2002. Social responsibility and supply chain relationships. Transportation Research Part E: Logistics and Transportation Review 38(1): 37-52.

Carter, C.R. and M.M. Jennings. 2004. The role of purchasing in corporate social responsibility: a structural equation analysis. Journal of Business Logistics 25(1): 145-186.

Centraal Bureau voor de Statistiek (CBS). 2014. Kerncijfers industrie: productie, omzet en orders. Available at: http://tinyurl.com/y8zvw33k.

Chkanikova, O. 2016. Sustainable purchasing in food retailing: interorganizational relationship management to green product supply. Business Strategy and the Environment 25: 478-494 
Cousins, P.D., B. Lawson and B. Squire. 2006. An empirical taxonomy of purchasing functions. International Journal of Operations and Production Management 26(7): 775-794.

Cox, A. 1996. Relational competence and strategic procurement management. European Journal of Purchasing and Supply Management 2(1): 57-70.

Crespin-Mazet, F. and E. Dontenwill. 2012. Sustainable procurement: building legitimacy in the supply network. Journal of Purchasing and Supply Management 18(4): 207-21.

Duffy, R., A. Fearne, S. Hornibrook, K. Hutchinson and A. Reid. 2013. Engaging suppliers in CRM: The role of justice in buyer-supplier relationships. International Journal of Information Management 33(1): 20-27.

Dyer, J.H. and H. Singh. 1998. The relational view: cooperative strategy and sources of interorganizational competitive advantage. The Academy of Management Review 23(4): 660-679.

European Commission (EC). 2014. What is an SME?. Available at: http://tinyurl.com/ydhyksoc.

Ellram, L.M., W. Tate and C. Billington. 2007. Service supply management: the next frontier for improved organizational performance. California Management Review 49(4): 44-66.

Erich, M. 2012. Food 2030. Samenwerking vanuit een nieuwe mindset. ING Economisch Bureau. Available at: http://tinyurl.com/yazf4rre.

Fawcett, S.E., C. Wallin, C. Allred, A.M. Fawcett and G.M. Magnan. 2011. Information technology as an enabler of supply chain collaboration: a dynamic-capabilities perspective. Journal of Supply Chain Management 47(1): 38-59.

Fawcett, S.E., P. Osterhaus, G.M. Magnan, J.C. Brau and M.W. McCarter. 2007. Information sharing and supply chain performance: the role of connectivity and willingness. Supply Chain Management 12(5): 358-368.

Gellynck, X., A. Banterle, B. Kuhne, L. Carraresi and S. Stranieri. 2012. Market orientation and marketing management of traditional food producers in the EU. British Food Journal 114(4): 481-499

Genovese, A., S.C.L. Koh, G. Bruno and E. Esposito. 2013. Greener supplier selection: state of the art and some empirical evidence. International Journal of Production Research 51(10): 2868-2886.

Gereffi, G., T. Humphrey and T. Sturgeon. 2005. The governance of global value chains. Review of International Political Economy 12(1): 78-104

Gold, S., S. Seuring and P. Beske. 2010. Sustainable supply chain management and inter-organizational resources: a literature review. Corporate Responsibility and Environmental management 17(4): 230-245.

González-Benito, J. 2007. A theory of purchasing's contribution to business performance. Journal of Operations Management 25(4): 901-917.

González-Benito, J. and Ó. González-Benito. 2006. A review of determinant factors of environmental proactivity. Business Strategy and the Environment 15(2): 87-102.

Govindan, K., S. Seuring, Q. Zhu and S. Garrido Azevedo. 2016. Accelerating the transition towards sustainability dynamics into supply chain relationship management and governance structures. Journal of Cleaner Production 112(3): 1813-1823.

Govindan, K., T. Khodaverdi and A. Jafarian. 2013. A fuzzy multi criteria approach for measuring sustainability performance of a supplier based on triple bottom line approach. Journal of Cleaner Production 47: 345-354.

Grekova, K., H.J. Bremmers, J.H. Trienekens, R.G.M. Kemp and S.W.F. Omta. 2014. Extending environmental management beyond the firm boundaries: an empirical study of Dutch food and beverage firms. International Journal of Production Economics 152: 174-187.

Grimm, J.H. and J.S. Hofstetter, J. Sarkis. 2014. Critical factors for sub-supplier management: a sustainable food supply chains perspective. International Journal of Production Economics 152: 159-173.

Gualandris, J., R. Golini, M. Kalchschmidt. 2014. Do supply management and global sourcing matter for firm sustainability performance?. Supply Chain Management 19(3): 258-274.

Handfield, R.B., S.V. Walton, R. Sroufe and S.A Melnyk. 2002. Applying environmental criteria to supplier assessment: a study in the application of the Analytical Hierarchy Process. European Journal of Operational Research 141(1): 70-87. 
Hoejmose, S., S. Brammer and A. Millington. 2012. 'Green' supply chain management: The role of trust and top management in B2B and B2C markets. Industrial Marketing Management 41(4): 609-620.

Hoejmose, S.U. and A.J. Adrien-Kirby. 2012. Socially and environmentally responsible procurement: A literature review and future research agenda of a managerial issue in the $21^{\text {st }}$ century. Journal of Purchasing and Supply Management 18(4): 232-242.

Hoejmose. S.U., J. Grosvold and A. Millington. 2013. Socially responsible supply chains: power asymmetries and joint dependence. Supply Chain Management 18(3): 277-291.

Hollos, D., C. Blome and K. Foerstl. 2012. Does sustainable supplier co-operation affect performance? Examining implications for the triple bottom line. International Journal of Production Research 50(11): 2968-2986.

Industrial Research Institute (IRI) 2014. Sustainability maturity model. Available at: http://www.iriweb.org/ research-sustainability-maturity-models.

Jabbour, A.B., C. Jabbour, K. Govindan, D. Kannan and A.F. Arantes. 2014. Mixed methodology to analyze the relationship between maturity of environmental management and the adoption of green supply chain management in Brazil. Resources, Conservation and Recycling 92: 255-267

Kraljic, P. 1983. Purchasing must become supply management. Harvard Business Review 61(5): 109-117.

Krause, D.R., S. Vachon and R.D. Klassen. 2009. Special topic forum on sustainable supply chain management: introduction and reflections on the role of purchasing management. Journal of Supply Chain Management 45(4): 18-25.

Lambert, D. and M.C. Cooper. 2000. Issues in supply chain management. Industrial Marketing Management 29: $65-83$

Lee, S.-Y. 2008. Drivers for the participation of small and medium-sized suppliers in green supply chain initiatives. Supply Chain Management 13(3): 185-198.

Lee, S.-Y. and R.D. Klassen. 2008. Drivers and enablers that foster environmental management capabilities in small- and medium-sized suppliers in supply chains. Production and Operations Management 17(6): 573-586.

Makkonen, H. and M. Vuori. 2014. The role of information technology in strategic buyer-supplier relationships. Industrial Marketing Management 43(6): 1053-1062.

Meyers, L.S., G. Gamst and A.J. Guarino. 2012. Applied Multivariate Research: Design and Interpretation ( $2^{\text {nd }}$ ed.). SAGE Publications, Thousand Oaks, CA, USA.

Miemczyk, J., T.E. Johnsen and M. Macquet. 2012. Sustainable purchasing and supply management: a structured literature review of definitions and measures at the dyad, chain and network levels. Supply Chain Management 17(5): 478-496.

Müller, A. and R. Pfleger. 2014. Business transformation towards sustainability. Business Research 7(2): 313-350.

Nordin, F. and H. Agndal. 2008. Business service sourcing: a literature review and agenda for future research. International Journal Integrative Supply Management 4(3/4): 378-405.

Nunnally, J.C. 1978. Psychometric Theory ( $2^{\text {nd }}$ ed.). Tata McGraw-Hill, New Delhi, India.

Okongwu, U., R. Morimoto and M. Lauras. 2013. The maturity of supply chain sustainability disclosure from a continuous improvement perspective. International Journal of Productivity and Performance Management 62(8): 827-855.

Oruezabala, G. and J. Rico. 2012. The impact of sustainable public procurement on supplier management The case of French public hospitals. Industrial Marketing Management 41(4): 573-580.

Pagell, M., Z. Wu. and M.E. Wasserman. 2010. Thinking differently about purchasing portfolios: an assessment of sustainable sourcing. Journal of Supply Chain Management 46(1): 57-73.

Park, H. and L. Stoel. 2005. A model of socially responsible buying/sourcing decision-making processes. International Journal of Retail and Distribution Management 33(4): 235-248.

Paulraj, A., A.A. Lado and I.J. Chen. 2008. Inter-organizational communication as a relational competency: antecedents and performance outcomes in collaborative buyer-supplier relationships. Journal of Operations Management 26(1): 45-64.

Preuss, L. 2009. Addressing sustainable development through public procurement: the case of local government. Supply Chain Management 14(3): 213-223. 
Rao, P. 2002. Greening the supply chain: a new initiative in South East Asia. International Journal of Operations and Production Management 22(6): 632-655.

Reuter, C., K. Foerstl, E. Hartmann and C. Blome. 2010. Sustainable global supplier management: The role of dynamic capabilities in achieving competitive advantage. Journal of Supply Chain Management 46(2): 45-63.

Rota, C., N. Reynolds and C. Zanasi. 2013. Sustainable food supply chains: the role of collaboration and sustainable relationships. International Journal of Business and social Science 4(4): 45-53.

Sarkis, J., Q. Zhu and K. Lai. 2011. An organizational theoretic review of green supply chain management literature. International Journal of Production Economics 130(1): 1-15.

Schiemann, M. 2007. Inter-enterprise relations in selected economic activities. Eurostat 57: 1-8. Available at: http://tinyurl.com/y8jbjb69.

Schneider, L. and C.M. Wallenburg. 2012. Implementing sustainable sourcing - Does purchasing need to change? Journal of Purchasing and Supply Management 18(4): 243-257.

Seuring, S. and M. Müller. 2008. From a literature review to a conceptual framework for sustainable supply chain management. Journal of Cleaner Production 16(15): 1699-1710.

Spekman, R.E. and R. Carraway. 2006. Making the transition to collaborative buyer-seller relationships: an emerging framework. Industrial Marketing Management 35(1): 10-19.

Sucky, E. and S.M. Durst. 2013. Supplier development: current status of empirical research. International Journal of Procurement Management 6(1): 92-127.

Tate, W.L., L.M. Ellram and K.J. Dooley. 2012. Environmental purchasing and supplier management (EPSM): theory and practice. Journal of Purchasing and Supply Management 18(3): 173-188.

Van Marrewijk, M. 2005. A developmental approach towards corporate sustainability: the European corporate sustainability framework for managing complexity and corporate transition. Journal of Ethical Management Decision Making 6(3/4): 257-272.

Varoutsa, E. and R.W. Scapens. 2015 The governance of inter-organisational relationships during different supply chain maturity phases. Industrial Marketing Management 46: 68-82

Wagner, S.M. 2011. Supplier development and the relationship life-cycle. International Journal of Production Economics 129(2): 277-283.

Walker, H., J. Miemczyk, T. Johnsen and R. Spencer. 2012. Sustainable procurement: past, present and future. Journal of Purchasing and Supply Management 18(4): 201-206.

Wu, Z., Pagell, M. 2011. Balancing priorities: decision-making in sustainable supply chain management. Journal of Operations Management 29(6): 577-590.

Yu, W., R. Chavez, M. Feng and F. Wiengarten. 2014. Integrated green supply chain management and operational performance. Supply Chain Management 19(5-6): 683-696.

Zsidisin, G.A. and T.E. Hendrick. 1998 Purchasing's involvement in environmental issues: a multi-country perspective. Industrial Management and Data Systems 98(7): 313-320. 
